Opening the meeting for general diseussion, Dr. Bullerwell recalled a remark of Prof. Bruckshaw that potential theory has been known a very long time and that in many fields interpretation shows no fundamental advance over the past fifteen years. Noting that during this period there has been increased use of systems like the airborne magnetometer for recording continuous profiles, he asked whether these removed some of the subjective elements mentioned. Prof. Bruckshaw replied that the subjective element, remains in spite of such developments, due to the gaps between profiles and uncertainties in completing contours. Though coverage is improved, it is never complete. Dr. W. Domzalski felt that some views expressed had been unduly pessimistic. Even though interpretations might prove quantitatively in error, qualitative results obtained following an imaginative approach often lead to new discoveries. For reasonable success in interpretation it is also important to choose the geophysical method most suited to the geological problem. Even where no control information to guide the interpretation is available, the possible results may justify geophysical work as the most economical means of preliminary reconnaissance. On the question of economics, Dr. Bullerwell asked how soon during a survey should the results be tested by drilling. Mr. N. I.. Falcon said that satisfactory exploration implies a balanced programme combining geology, geophysics and drilling. It is desirable to establish control, pursue the investigation comprehensively and not anticipate conclusions on the basis of too few results, but geophysical interpretation remains speculative until the key localities are drilled. Dr. T. C. Richards said that geophysical experiences in Canada emphasize the importance of early dilling control. A quantitative approach is essential throughout and second-derivative gravity maps have proved unreliable for this. Seismic methods must be intro. duced at a very early stage and have adequate geological and drilling control, especially in the Reef field, to overcome difficulties due to facies changes. Otherwise, occurrences of Reef limestone in limestone or local velocity anomalies, as at Swan Hills, Alberta, would not be recognized.

In closing the meeting the chairman remarked that personal experience often decides for one interpretation method rather than another. Perhaps a real advance during the past fifteen years is represented by pooling of experience through free discussion and improved publication of geophysical results. There is certainly a clear recognition of fundamental problems.

\title{
TWELFTH INTERNATIONAL ASTRONAUTICAL CONGRESS
}

$\mathrm{T}$ HE International Astronautical Congress is an annual meeting of the interplanetary societies of the world. Societies take it in turn to act as host, and the recent meeting, during October 1-7, in Washington, was the first occasion that the meeting had been held on the American continent. Next year's conference was fixed for Sofia, Bulgaria, it having been held in Stockholm last year and London in 1959. Of the 750 people registered, some 300 came from outside the United States. The president of the International Astronautical Congress this year was Academician L. I. Sedov, of the U.S.S.R., and for the forthcoming year Prof. J. Pérès, of France, was appointed the new president.

The week following the Congress was the occasion of a meeting in New York by the American Rocket Society - "Spaceflight Report to the Nation".

There was perhaps a feeling that the International Astronautical Congress was of not quite such a high technical standard as previous ones, as many Americans seemed to consider the American Rocket Society meeting to be the more important of the two-a view not altogether shared by the European delegates.

The opening ceremony on Monday was followed by a reception and buffet at the Bolling Air Force Base, where Dr. Theodore von Kármán was very much in evidence among the delegates.

The technical sessions started at 9 a.m. on October, 3 with three simultaneous sessions on space propulsion, astrodynamics and guidance, and the Fourth Colloquium on the Law of Outer Space (the Third Colloquium was held in Stockholm in 1960).

The session on space propulsion had two lectures from British delegates, the first by Mr. A. W. T. Mottram (Bristol Siddeley Engines, Ltd., Coventry) entitled: "Propulsion of the Final Stage of a Satellite Launcher using Liquid Hydrogen as Fuel". Although this was the first lecture of the morning, it was well attended and there was a good discussion, although
Americans in the audience were perhaps a little reluctant to describe some of their more recent failures in this field. It must be remembered that liquid hydrogen has not yet been used successfully to place a satellite in orbit, and that it was announced during the course of the Congress that the Centaur rocket using liquid hydrogen as a fuel has been officially set back eight months.

The other British paper, "An Examination of the Characteristics of Propulsion Systems for InterOrbital Transfer", by P. A. E. Stewart (Hawker Siddeley Aviation) was read in his absence by his colleague, Dr. W. F. Hilton. This described the more exotic forms of propulsion, including an omnidirectional method of focusing the Sun's rays for the direct heating of liquid hydrogen for use as a working substance.

Undoubtedly the most noteworthy paper of the morning was by another British delegate, Arthur C. Clarke (Clarke-Wilson Associates, Colombo), under the title "The Social Impact of Communications Satellites". This was presented during the Space Law Colloquium and attracted widespread interest. A future state of affairs where worldwide communications are as cheap and reliable as our present local communications was investigated, and its effects on social behaviour and trade were discussed. $\mathrm{Mr}$. Clarke is, of course, well known for having started the idea of communications satellites by his article in October 1945 in The Wireless World, and indeed a reprint of this article wes issued to all delegates.

The Space Law Colloquium continued in the afternoon and there was a session on energy conversion and yet another simultaneous session on astrodynamics and guidance. This last subject was treated as a round-table topic where a number of contributors made both prepared and unprepared comments, and included Prof. Zdenek Kopal (University of Manchester). 
On October 4 the round-table concept was continued with a discussion on exploration of the solar system by radar and radio astronomy, the Moon and Venus being considered in the morning and Jupiter and future experiments in the afternoon. The radio reflexion experiments from the surface of the Moon appear to show fairly conclusively that much of the Moon is covered with a layer of dust having a thickness less than $1 \mathrm{~cm}$. The session on Jupiter was of interest on account of the detailed deseription of the radio emissions from the Great Red Spot. The nature of these emissions is now fairly well established, but their cause appears to remain a mystery.

The most significant communication at the Conference was given by the Russian delegation, who revealed that their cosmonaut Titov was space-sick throughout the duration of his 24-hr. trip around the Earth, although this did not prevent him from sleep. ing in accordance with plans, or from carrying out routine duties which had been assigned to him.

On October 5 the weather was fortunately much better, and the now traditional conforence boat-trip was made down the River Potomac past the Naval Research Laboratory's radio telescope, on to Mount Vernon. This informal occasion probably gives more opportunity for relaxed discussion between ad hoc groups of experts than is possible in the more formal atmosphere of the conference hall. The Congress banquet was held in the evening and was addressed by Academician Sedov.
On October 6 another British paper was presented, "Blue Streak as First Stage of a Satellite Launcher", by G. K. C. Pardoe. This described the present position of Britain's only large rocket, based on the design of the American Atlas rocket, which is the largest they have attempted to fire to date. No particular reference was made to possible British or European payloads, although possible European collaboration in the future was mentioned. Simul. taneously, there was a round-table meeting on space communications, but most amazingly no reference was made to the use of radio, which is of course the obvious way for exploiting space for communications purposes. The signals to be conveyed would be modulated on to bcams of light emitted from optical masers. This method gives a promise of tremendous band-width at some remote time in the future. Use of ultraviolet light for communications was proposed by Mr. J. W. Ogland, and one rather speculative paper suggested the use of $\gamma$-rays for communications. If the vehicle is propelled by a nuclear rocket, the $\gamma$-rays are available as a by-product and some form of hinged lead sheet has to be contrived for signalling purposes. This method is limited to use in space in the absence of any atmosphere and was shown to work at ranges up to 100,000 miles, but the signalling frequency is limited to one cycle per second.

Finally, on Octoker 7 , delegates were taken on a tour of the NASA Goddard Space Flight Center at Goddard, Maryland. W. F. Hilton

\section{THE VEHICLE DRIVER}

A MEETING of the British Occupational Hygiene Society was held at the Traffic and Safety Division of the Road Research Laboratory during November 9-10. Six papers were read and discussed; for the first two, which dealt with bus drivers, the chair was taken by Dr. L. G. Norman, the president of the Society.

Examination by Dr. P. Froggatt of data from Northern Ireland revealed that a curve of accidentrate plotted against age of driver had a broad minimum over the ages $45-55$ years which was due to the beneficial results of experience being opposed by the decline in performance with advancing age. The accident-rate of experienced drivers rose above $\mathbf{5 0}$ vears of age.

Mr. C. J. Cornwall had examined the records of London bus drivers for the poriod 1957-59 for which the average rate was 1.37 accidents per driveryear on a mileage of about 14,000. Accidents were associated with traffic density. The accident-rate fell with increasing experionce more rapidly than it rose with age; the fall was marked up to 47 years and slower up to 70. Replacements of old drivers by younger men would increase the number of accidents.

Dr. R. J. Smeed, deputy director of the Road Rosoarch Laboratory, occupied the chair during a session which was opened by Mr. W. Gissane, who described the nature and cause of injuries resulting from motor-car accidents in a city. SquadronLeader D. I. Fryer told of the development of safety belts in aircraft, going back to Colonel Cody, who was the first man to fly a powered machine in England. The design and testing of modern safety-belts were described in detail, and tho value of rearwardsfacing seats, adequately attached to the airframe, was emphasized.
Road experience with safety bolts was dealt with by Dr. A. J. Moroland, who approached the problem of assessing accidents quantitatively by defining a damage index. This number was evaluated from the damage to chassis, compartment and bodywork. When divided by the weight of the motor-ear it correlated well with the difference between the squares of the velocities of the objects coming into contact.

The damage index divided by weight was used as a basis for comparing the frequency of casualties of various degrees. Fatalities commenced at a figure near 15 and rose steadily; serious injuries rose from near the origin while slight injuries attained a maximum at about 25 .

Safety belts of good design, firmly attached, could prove beneficial, but there were suggestions that people drove faster when wearing them, and they did not check the forward velocity of the head on impact or protect it from objects flung forward from the rear. The steering arrangements, likewise, might either promote injury or provide protection.

The final paper was delivered by $\mathrm{Mr}$. I. D. Brown with Prof. D. D. Reid in the chair. Observations of police and other skilled drivers had been used in an attempt to relate driving performance to fatigue and distraction. It seemod likely that there was spare capacity to draw on in case of need and that fatigue from general occupations before driving might be more serious than that induced by driving. Tosts of distraction by using tape recordings in which the subject was either interested, or not interested, were also carried out.

The Road Research Laboratory demonstrated the telemetering of movements of the controls of a vehicle under way, of recording what happens in an accident and of experimental collisions. The incorrect basis of 